\title{
A 23911 bp region of the Bacillus subtilis genome comprising genes located upstream and downstream of the lev operon
}

\author{
Víctor Parro, ${ }^{1}$ Marta San Román, ${ }^{1}$ Inmaculada Galindo, ${ }^{1}$ \\ Bénédicte Purnelle, ${ }^{2}$ Alexander Bolotin, ${ }^{3}$ Alexei Sorokin ${ }^{3}$ and \\ Rafael P. Mellado'
}

Author for correspondence: Rafael P. Mellado. Tel: +341 5854547. Fax: +3415854506. e-mail:rpmellado@samba.cnb.uam.es

1 Centro Nacional de Biotecnología (CSIC), Campus de la Universidad Autónoma, Cantoblanco, 28049 Madrid, Spain

2 Unité de Biochimie Physiologique, Université Catholique de Louvain, Place Croix-du-Sud, 2/20, 1348 Louvain-la-Neuve, Belgium

3 Laboratoire de Génétique Microbienne, INRA, Domaine de Vilvert, 78352 Jouy-en-Josas cedex, France

\begin{abstract}
Within the framework of the European project to sequence the whole Bacillus subtilis 168 genome, a 23911 bp long chromosomal DNA fragment located around $233^{\circ}$ on the $B$. subtilis genetic map was cloned and sequenced. From the generated sequencing data and the results of the homology search, the primary structure of this region was determined. In addition to the whole lev operon, the region contains putative genes for an amino acid permease, two different alcohol dehydrogenases, a chitosanase, a protein belonging to the LysR family of transcriptional regulators, a protein related to the MerR transcriptional regulator, up to four proteins related to the product of the spoF gene, and genes coding for nine more inferred proteins of unknown function.
\end{abstract}

Keywords: Bacillus subtilis, genomic sequencing, adh, cns, lysR family

\section{INTRODUCTION}

The structural gene for the enzyme levanase of Bacillus subtilis $(\mathrm{sacC})$ is the distal gene of a fructose-inducible operon containing five genes, levD, levE, levF, levG and sacC (Martín-Vestraete et al., 1990); this operon is regulated at the transcriptional level by the product of the gene $l e v R$, which precedes the operon in the $B$. subtilis genome (Débarbouillé et al., 1991). The region of the genome assigned to us as part of the European $B$. subtilis genome sequencing project contains $s a c C$, the last gene of the lev operon, located at $233^{\circ}$ on the B. subtilis chromosome (Martín et al., 1987). We have chosen $s a c C$ and levR whose sequences are known (Martín et al., 1987; Débarbouillé et al., 1991) as the points to start sequencing in both directions, continuing downstream from $s a c C$ and upstream from levR. By walking in this way along the $B$. subtilis chromosome we were able to determine the sequence of a contiguous region of $23911 \mathrm{bp}$ that contains the entire lev operon and apparently possesses coding capacity for an additional 19 proteins.

The EMBL accession number for the nucleotide sequence reported in this paper is X92868.

\section{METHODS}

Bacterial strains and plasmids. B. subtilis 168 (trpC2; Anagnostopoulos et al., 1993) was the source of genomic DNA and was provided by F. Kunst. Escherichia coli NM514 was used for the propagation of plasmid pRM1 (R.P. Mellado, unpublished), which contains the pUC18 polylinker (Norrander et al., 1983) and is a derivative of pRM1cat (Parro et al., 1991) from which the cat gene has been removed. E. coli XL1-Blue (Stratagene) was used to propagate pUC19. Plasmid pRL2 (a gift from G. Rapoport; Martín et al., 1987) was used as a source of $B$. subtilis DNA.

Standard media and DNA manipulations. Procedures for the growth and manipulation of E. coli and B. subtilis, and general recombinant DNA manipulations were as described elsewhere (Sambrook et al., 1989; Harwood \& Cutting, 1990). DNA was isolated from B. subtilis or E. coli cultures grown in LB at $37^{\circ} \mathrm{C}$. When necessary, ampicillin $\left(100 \mu \mathrm{g} \mathrm{m}^{-1}\right)$ was added to the cultures.

Genome libraries. Genome libraries on plasmid pRM1 were made by cloning gel-purified $4-8 \mathrm{~kb}$ long chromosomal DNA fragments produced by digestion with HindIII. A Sau3A genome library made in bacteriophage lambda GEM11 (a gift from C. Harwood), containing clones harbouring $10-15 \mathrm{~kb}$ long inserts of $B$. subtilis chromosomal DNA, was also screened for recombinant phages containing sequences around the lev operon. When chromosome walking by cloning of the DNA fragments was not possible, large pieces of chromosomal 
DNA were generated by inverse long-range PCR (Barnes, 1994; Cheng et al., 1994). Up to $10 \mu \mathrm{g}$ purified chromosomal DNA was digested with $K p n I$, ligated and then subjected to several cycles of PCR amplification (GeneAmpXL kit, Perkin Elmer) using the oligonucleotide primers K1 (AAGAACGGAGTCAGAAATTATGCG) and LR1 (CGATACTAGTTCAAACATGTACGG) from positions 13412 to 13389 and 13848 to 13871 of the sequenced DNA, respectively. The amplified DNA fragment was purified and its sequence (ACTAGTGAGTGCTACAATAACGGG) determined by extension of the $\mathrm{K} 1$ primer. This fragment was designated K3. Ten micrograms of chromosomal DNA was then subjected to PCR amplification using oligonucleotides K3 and LR 1 as primers in 10 separate identical reactions. The resulting amplified material was pooled and used as substrate for direct sequencing or cloning. Pooling together the separated reactions minimized the probability of sequencing putative single point mutations arising during the amplification procedure. The pooled DNA was digested with DNase and resulting $0.5-0.8 \mathrm{~kb}$ long DNA fragments were purified and blunt-end inserted into plasmid pUC18 (Ready-To-Go, Pharmacia) through its unique SmaI site. The ligation mixture was used to transform $E$. coli XL1-Blue and the recombinant clones randomly sequenced.

DNA sequencing and computer analysis of sequences. Sequencing of DNA was by the dideoxy chain-termination method (Sanger et al., 1977), using the 7 -deaza-dGTP reagent kit from US Biochemical as recommended by the manufacturer. Direct and reverse pUC19 primers (fmol kit, Promega) were used to randomly sequence the recombinant plasmids generated by the DNase treatment. Purified recombinant lambda or plasmid DNA was sequenced extending synthetic oligonucleotide primers (Isogen) using PCR (fmol kit, Promega). Alternatively, recombinant plasmid DNA was extracted from freshly grown colonies, in which case, cells were dispersed in $12 \mu \mathrm{l}$ lysis solution $(10 \mathrm{mM}$ Tris $/ \mathrm{HCl}$ $\mathrm{pH} 7 \cdot 5,1 \mathrm{mM}$ EDTA, $50 \mu \mathrm{g}$ proteinase $\mathrm{K} \mathrm{ml}^{-1}$ ) by vortexing, incubated for $15 \mathrm{~min}$ at $55^{\circ} \mathrm{C}$ and the proteinase $\mathrm{K}$ inactivated by further incubation at $80^{\circ} \mathrm{C}$ for an additional $15 \mathrm{~min}$; the mixture was cooled by addition of $20 \mu \mathrm{l}$ sterile water and incubated on ice for $1 \mathrm{~min}$ before centrifugation at $12000 \mathrm{~g}$ for $3 \mathrm{~min}$ at room temperature. Ten microlitres of the resulting supernatant was used for the cycle sequencing following the supplier's recommendations. In all three cases, the sequencing mixtures were heated at $94^{\circ} \mathrm{C}$ for $2 \mathrm{~min}$, then subjected to 30 cycles of incubation at $94^{\circ} \mathrm{C}(1 \mathrm{~min}), 50^{\circ} \mathrm{C}(1 \mathrm{~min})$, and $72{ }^{\circ} \mathrm{C}$ ( $2 \mathrm{~min}$ ) before allowing the reaction to cool down at $4{ }^{\circ} \mathrm{C}$.

Sequence alignments were done using the program FRAGMENT ASSEMBLY from the UWGCG package and XDAP (Dear \& Staden, 1991). The DNA sequence was analysed for ORFs using CODON PREFERENCE (UWGCG) and XNIP (Dear \& Staden, 1991). Amino acid sequences were analysed using programs from the UWGCG package (version 8.0, September 1994). Protein sequences were compared with the PIR and SWISS-PROT protein databases using the FASTA algorithm (Pearson \& Lipman, 1988).

\section{RESULTS AND DISCUSSION}

\section{Cloning, physical mapping and sequencing of genomic DNA}

Two synthetic oligonucleotides, GACGGGAGCGAGTCAGGC and GCGATCGCCCTCGGCCTC, were used to synthesize the DNA between them by PCR amplification, and the amplified region, encoding part of the carboxyl end of the B. subtilis levanase (SacC), was gel-purified to be used as a probe. Genomic DNA was digested with the restriction endonuclease HindIII and subjected to Southern blotting hybridization. DNA, 6-8 kb long, hybridizing to the probe, was purified and inserted into the plasmid pRM1 through its unique HindIII site and the recombinant plasmids propagated in E. coli. The pre-sized genome library was then screened with the same probe. The selected recombinant plasmid pSU1000 contained the whole sacC gene as expected, the approximately $6.5 \mathrm{~kb}$ long insert spanning over $3.8 \mathrm{~kb}$ downstream of $s a c C$ (Fig. 1). This $3.8 \mathrm{~kb}$ long region was entirely sequenced, extending 23-24 nt long oligonucleotide primers generated as the sequencing proceeded (Fig. 1). The rest of $B$. subtilis DNA contained in plasmid pRL2, including the lev operon, was sequenced in the same manner.

The $1.5 \mathrm{~kb}$ long Pst $-E c o$ RI fragment upstream of the lev operon (P-E, Fig. 1) was used as a probe to screen the lambda GEM11 library. Among the five selected recombinant phages only lambda L1003 contained DNA not previously cloned; the 888 bp long Sau3A-Pst I fragment (S-P, Fig. 1) situated within the $12 \mathrm{~kb}$ long insert of lambda L1003 was sequenced directly from the phage DNA.

Up to 90 different clones obtained from the inverse-longrange-PCR-amplified chromosomal DNA (KpnI sites K1-K2, Fig. 1) were randomly sequenced; sequence alignment of the generated sequences allowed us to specifically derive 23-24-mer oligonucleotides that were used as primers to fill up the gaps and to link the different aligned contigs. This region was also sequenced using the BA4 $\times$ AA3 fragment generated by PCR as described by Bolotin et al. (1996). On average, both strands of the resulting DNA were sequenced between two and three times. The base composition of the sequenced DNA was $41.2 \mathrm{~mol} \% \mathrm{G}+\mathrm{C}$, close to the value of $42 \mathrm{~mol} \% \mathrm{G}+\mathrm{C}$ of the $B$. subtilis genome as a whole (Sharp et al., 1990).

\section{Identification of ORFs}

Putative ORFs were searched for in all possible reading frames. Twenty-five putative ORFs were identified based on the length of the ORF and the presence of a preceding RBS (Table1). The initiation codons for two of them were TTG, the other 23 started with ATG. Suitable RBS sequences were found in all cases except yraC. ORFs yraB, yraH-J, csn and yraN-O are transcribed in the same sense as the lev operon, the rest of the ORFs are transcribed in the opposite orientation.

Table 2 shows putative $\rho$-independent transcription terminator sites identified behind ORFs other than those included in the lev operon. Putative promoter-like regions containing $B$. subtilis major RNA polymerase holoenzyme -10 consensus sequences were identified in front of aapA (TATAAT), csn (TATACT) and yraN (TATAAT), but the corresponding -35 consensus 


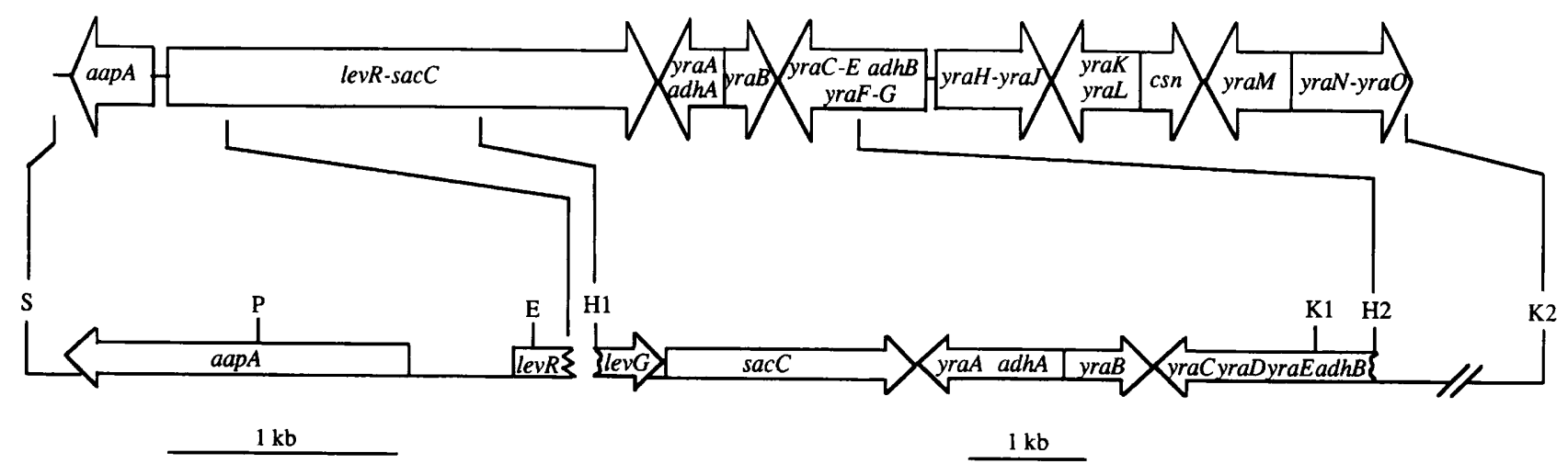

Fig. 1. Physical map and ORF organization of the sequenced region. The upper part shows the ORFs contained in the $23911 \mathrm{bp}$ long contig. Regions upstream and downstream of the lev operon are shown enlarged in the lower part. The arrows indicate the direction of transcription. S, Sau3A; P, Pstl; E, EcoRI; H, HindIII; K, Kpnl.

Table 1. ORFs in the $23911 \mathrm{bp}$ sequence around the $233^{\circ}$ region of the $B$. subtilis chromosome

\begin{tabular}{|lrll|}
\hline ORF & Endpoints $(\mathbf{b p})$ & Size $(\mathbf{a a})$ & \multicolumn{1}{c|}{ Translation start } \\
\hline AapA & $379-1755$ & 459 & tactGGAGGaaaataaaTTG \\
LevR & $2472-5285$ & 938 & atctaatAAGGAcaaaggATG \\
LevD & $5478-5915$ & 146 & aggaAAGGAGcaatagatATG \\
LevE & $5918-6403$ & 162 & aagagAGGAtGaattatgATG \\
LevF & $6423-7229$ & 269 & aatcAAGGgGaTGagaatATG \\
LevG & $7253-8077$ & 275 & gatgAGGgGGaagaaaaaATG \\
SacC & $8237-10267$ & 677 & agAGGAGcgaaggaacaaATG \\
YraA & $10361-10822$ & 154 & ttattAGGAGGgtttttATG \\
AdhA & $10956-12002$ & 349 & aagaAAGGAtagGttcgtATG \\
YraB & $12510-12929$ & 140 & gatAgaGAGGTGaagatcATG \\
YraC & $12915-13187$ & 91 & ccAacccttTaacatacaATG \\
YraD & $13197-13493$ & 99 & tgAGGAGaTGaataaatcATG \\
YraE & $13512-13706$ & 65 & aaaAcGGAGGTtacagaaATG \\
AdhB & $13728-14861$ & 378 & cactGGAGGTttacagcATG \\
YraF & $14883-15248$ & 122 & aaAgGGAGGTaagcctctTTG \\
YraG & $15269-15511$ & 81 & aAAGGAGGTtacatcaatATG \\
YraH & $15760-16143$ & 128 & ttatAGGAGGcactcgatATG \\
YraI & $16587-17018$ & 144 & tatgGGAGGgGagggggcATG \\
YraJ & $17068-17427$ & 120 & ggaattgAAGaAaGaGggATG \\
YraK & $17966-18652$ & 229 & gaAAGGAaGgtcctacaaATG \\
YraL & $18792-19052$ & 87 & aatAAGGAGcTGgcagaaATG \\
Crn & $19495-20325$ & 277 & ttagaAAGGgGaaGtgaaATG \\
YraM & $20604-21704$ & 367 & aagAtGAGGatgatgacgATG \\
YraN & $21849-22715$ & 289 & ctagaAAGGAaGatgaaaATG \\
YraOt & $22833-23911$ & 359 & cattcttGGAGGTGtaatATG \\
\hline
\end{tabular}

* Putative initiation codons are shown in upper case bold. Nucleotides conserved from the consensus RBS sequence AAGGAGGTG are shown in upper case.

†Partial ORF.

sequences did not seem to be present. yraH and yral have -35 consensus sequences (TTGACA and TTGAAA, respectively) in front of them, but they lack the corresponding -10 ones. Putative -35 regions likely to be recognized by other sigma factors appeared in front of yraL and yraM (CTAAA, sigma D) or $a d b A$ (AGGTTT, sigma B), but again the corresponding -10 regions seemed to be missing. Transcription initiation and termination mapping experiments are needed to ascertain these possibilities. 
Table 2. Putative $\rho$-independent transcription terminators

Inverted repeats are indicated in upper case.

\begin{tabular}{|ll|}
\hline ORF & \multicolumn{1}{c|}{ Putative $\rho$-independent transcription terminator } \\
\hline AapA & cgaaATAaaAAAAGACAAGGGAtactcacTCCCTTGTCTTTTTaTATgtgtc \\
YraA & ataacAAGAAGGCACAGACTgttcgGGTCTGTGCCTTTTTtaaaa \\
AdhA & cggtcAATCTTCCTGttATTCTatgaatagAGAGTtatTAGGAGGGTTttta \\
YraB & tgcgtGTGaAGAGGGCAGGTCAaAAACGAaggattTTGTTTcTGGCCTGTTTTCTcCATcaaga \\
YraD & gattGCTGAGGAACAGTatTGattggcCAcaACTGTTCCTCAGCttcaa \\
AdhB & cgcctTAcACGAAGTGCTTGAGgttCAGgaaatgaCTGcaTTTAAGaCACTTTGTttgac \\
YraH & aggttGCGGACACTGaACttgCAGCatttacGCTGattGTaTGGTGTCCGTtttg \\
YraJ & gacgaACCATACCAACaacaataGTTGGTATGGTtttg \\
YraK & gggagCTtTTTCCttATcGTTgCGCgaacgctaGCGgAACaATtGGAAAcAGaatggg \\
YraL & aacggAAGCACTGATaaaaataATCAGTGCTTtttat \\
Csn & gatgaACTCAAtctAAAAGATACCAAtgatgTTGGTATCTTTTtatTTGcAGTaaaaa \\
YraM & atgtaGATGGACTGTGCAAaAAGCcTCccccttTCCATCgttaataGATGGAttGAatgcGCcTTcTTGCACAGaTCCA- \\
& TTgtaat \\
YraN & atttaAAGTTAtgATAGAatTTTTTTTGaaacacagTAAAAAAAtaTTTATtTAACTTattac \\
\hline
\end{tabular}

\section{Function of the newly identified ORFs}

The amino acid sequence of the putative product of each ORF was compared with the non-redundant protein databases and the results are summarized in Table 3. Apart from the ORFs included in the lev operon and its regulator levR (Martín et al., 1987; Débarbouillé et al., 1991), four more ORFs, aapA, adbA, adbB and csn, were found to have putative products similar to known enzymes and were named after them. Four other ORFs, yraD-G, showed homology to the two proteins encoded by the spoF gene (Cutting et al., 1991) and another one, $y \mathrm{raB}$, to the regulatory protein product of merR (Fleischmann et al., 1995). The putative polypeptide YraN seemed to be a member of the LysR family of transcriptional regulators and the product of y $\mathrm{raO}$ showed homology to the hypothetical one reported for the B. subtilis gene yxiQ (Yoshida et al., 1995; Wolf et al., 1995). YraA showed homology to a hypothetical $20.3 \mathrm{kDa}$ protein product of the $y b b \mathrm{O}$ gene from $E$. coli, as registered in the databases. No homologous polypeptides were found for the remaining seven putative ORF products.

aap $A$ encodes a polypeptide of 459 aa and its sequence showed homology with many amino acid permeases from E. coli, B. subtilis and Salmonella typhimurium with identity percentages ranging from 31.4 to $51 \cdot 8$; it showed the highest identity with the D-serine/Dalanine/glycine transporter from E. coli (Burland et al., 1995). The 349 aa long putative polypeptide encoded by adhA showed a high degree of homology $(61.8 \%$ identity) with a Mycobacterium bovis NADP-dependent alcohol dehydrogenase, belonging to the family of zinccontaining alcohol dehydrogenases, which is widely distributed among the eukaryotic and prokaryotic kingdoms; all the residues considered to be needed for enzyme activity (Stélandre et al., 1992) are also conserved. The putative protein encoded by $a d b B$ is 378 aa long and showed homology to another group of alcohol dehydrogenases (identity percentages between $27 \cdot 2$ and 30 in most cases), the NAD-dependent alcohol dehydrogenases, which are also widely distributed in nature. It showed the greatest homology with the enzyme from baltic cod Gadus callarias (Danielsson et al., 1992). The csn putative product, 277 aa long, showed homology $(36.4 \%$ identity) to the chitosanase product of the Streptomyces sp. csn gene (Masson et al., 1994).

$s p o F$ encodes a 160 aa long polypeptide that is cleaved to generate two spore coat proteins: one, with a molecular size of $5 \mathrm{kDa}$, containing residues 5-76 and another one of $8 \mathrm{kDa}$, containing the rest of the original molecule (Cutting et al., 1991). Two sets of two ORFs, yraG-yraF and yraE-yraD, flank $a d h B$ (see Fig. 1); yraG and yraE encode polypeptides homologous to the $5 \mathrm{kDa}$ protein (30.7\% and $40 \%$ identity, respectively), and $y \mathrm{raF}$ and $y \mathrm{raD}$ encode polypeptides homologous to the $8 \mathrm{kDa}$ protein $(39.9 \%$ and $40 \%$ identity, respectively). yraG and $y \mathrm{raE}$ are homologous but not identical proteins, as is also the case for $y \mathrm{raD}$ and $y \mathrm{raF}$. The chromosomal arrangement is such that the ORF for the $5 \mathrm{kDa}$-proteinlike product always precedes the ORF for the $8 \mathrm{kDa}$ protein-like product, as if this particular order has to be preserved. Perhaps the $5 \mathrm{kDa}$ and $8 \mathrm{kDa}$ proteins head two families of tightly linked proteins that need to be coordinately synthesized. The existence of an operon comprising yraG-yraF-adbB-yraE-yraD-yraC cannot be ruled out from the sequencing data, although yraC does not seem to have a consensus RBS preceding the translation start codon (Table 1).

The ORF $y r a N$ precedes $y r a O$, these being the two last ORFs at one of the ends of the 23911 bp long contig. The putative protein encoded by $y \mathrm{raN}$ is 289 a long and showed homology to proteins included in the prokaryotic LysR family of transcriptional regulators, particularly with the $B$. subtilis hypothetical YwbI 
Table 3. Comparison of predicted ORF products with protein database entries

\begin{tabular}{|c|c|c|c|}
\hline ORF $^{*}$ & Homologous protein & $\begin{array}{c}\text { Database } \\
\text { entry }\end{array}$ & $\begin{array}{c}\text { FASTA- } \\
\text { optimized } \\
\text { score } \dagger\end{array}$ \\
\hline AapA & Amino acid permease & P39312 & 1427 \\
\hline LevR & Transcriptional regulatory protein & P23914 & 4446 \\
\hline LevD & Fructose-specific IIA component & P26379 & 684 \\
\hline LevE & Fructose-specific IIB component & P26380 & 729 \\
\hline LevF & Fructose-specific IIC component & P26381 & 1254 \\
\hline LevG & Fructose-specific IID component & P26382 & 1427 \\
\hline $\mathrm{SacC}$ & Levanase precursor & P05656 & 3418 \\
\hline YraA & Hypothetical $20 \cdot 3 \mathrm{kDa}$ protein & P45470 & 255 \\
\hline AdhA & NADP-dependent alcohol dehydrogenase & P31975 & 1116 \\
\hline YraB & Mercury resistance operon regulatory protein & P22896 & 182 \\
\hline YraC & Unknown & & \\
\hline YraD & Spore coat protein $\mathrm{F}$ & P23261 & 172 \\
\hline YraE & Spore coat protein $F$ & P23261 & 105 \\
\hline AdhB & NAD-dependent alcohol dehydrogenase & P26325 & 313 \\
\hline YraF & Spore coat protein $\mathrm{F}$ & P23261 & 137 \\
\hline YraG & Spore coat protein $\mathrm{F}$ & P23261 & 111 \\
\hline YraH & Unknown & & \\
\hline YraI & Unknown & & \\
\hline YraJ & Unknown & & \\
\hline YraK & Unknown & & \\
\hline YraL & Unknown & & \\
\hline Csn & Chitosanase precursor & P33665 & 379 \\
\hline YraM & Unknown & & \\
\hline YraN & LysR family of transcriptional regulators & P39592 & 232 \\
\hline $\mathrm{YraO}$ & YxiQ, hypothetical $45.5 \mathrm{kDa}$ protein & P42308 & 1053 \\
\hline
\end{tabular}

*ORFs with a FASTA-optimized score below 150 were considered not to show homology with proteins contained in databases and therefore as previously unknown, with the exception of YraE, YraF and YraG (see text for details)

† Only the entry having the highest score is given.

protein (25.1\% identity, Glaser et al., 1993); YraO is an incomplete, 359 aa long polypeptide, showing homology (52.6\% identity) with the product of the B. subtilis yxiQ gene, a hypothetical integral membrane protein with a molecular size of $45.5 \mathrm{kDa}$ (Yoshida et al., 1995; Wolf et al., 1995); the potential transmembrane domains are conserved along the 359 aa overlap between the two proteins.

The putative product of $y \mathrm{raB}$ is a 140 aa long polypeptide that showed homology with the mercury resistance operon regulatory protein MerR from Haemophilus influenzae, Thiobacillus ferrooxidans, Bacillus sp. and Staphylococcus aureus $(29.0 \%, 29.6 \%$, $26.5 \%$ and $29.7 \%$ identity, respectively) and others; it showed the greatest homology with the hypothetical MerR (YhdM) from H. influenzae (Fleischmann et al., 1995). The YraB potential helix-turn-helix motif (residues 3-22) seemed to be conserved among all the proteins showing homology to MerR; although all the essential residues for the metal-binding properties of the regulatory protein seemed to be missing in both $\mathrm{YraB}$ and YhdM, and $y \mathrm{raB}$ does not precede the mer operon as reported in another Bacillus sp. (Wang et al., 1989).
The rest of the putative products encoded by ORFs in the sequenced region showed little homology with the proteins contained in the databases and were considered to be unknown proteins.

The average codon usage for all the ORFs does not differ much from the codon usage in any individual ORF (data not shown). However, the relative synonymous codon usage values, both average and individual, are very different from those of the highly expressed genes of B. subtilis (Sharp et al., 1990). This could suggest that the genes included in the sequenced region of the genome belong either to the class of $B$. subtilis genes that are constitutively expressed at a low level, or to a class which, if ever expressed, are tightly regulated.

\section{ACKNOWLEDGEMENTS}

We thank Dr Colin Harwood for the lambda GEM11 library and his hospitality to one of us in his laboratory, Dr Frank Kunst for the B. subtilis 168 strain and Dr George Rapoport for the plasmid pRL2. G. Villuendas, M. García and N. M. Romero performed some preliminary experiments. This research was supported by Grants BIO2-CT93-0272 from the UE and BIO94-1147-CE from the Spanish CICYT. 


\section{REFERENCES}

Anagnostopoulos, C., Piggot, P. J. \& Hoch, J. A. (1993). The genetic map of Bacillus subtilis. In Bacillus subtilis and Other Gram-positive Bacteria: Biochemistry, Physiology and Molecular Genetics, pp. 425-461. Edited by A. J. Sonenshein, J. A. Hoch \& R. Losick. Washington, DC: American Society for Microbiology. Barnes, W. M. (1994). PCR amplification of up to $35-\mathrm{kb}$ DNA with high fidelity and high yield from lambda bacteriophage templates. Proc Nat Acad Sci USA 91, 2216-2220.

Bolotin, A., Sorokin, A. \& Ehrlich, S. D. (1996). Mapping of the $150 \mathrm{~kb}$ spoIIIC-pheA region of the Bacillus subtilis chromosome using Long Accurate PCR and three yeast artificial chromosomes. Microbiology 142, 3017-3020.

Burland, V., Plunkett, G., III, Sofia, H. J., Daniels, D. L. \& Blattner, F. R. (1995). Analysis of the Escherichia coli genome. VI. DNA sequence of the region from 92.8 through 100 minutes. Nucleic Acids Res 23, 2105-2119.

Cheng, S, Higuchi, R. \& Stoneking, M. (1994). Complete mitochondrial genome amplification. Nat Genet 7, 350-351.

Cutting, S., Zheng, L. \& Losick, R. (1991). Gene encoding two alkali-soluble components of the spore coat from Bacillus subtilis. J Bacteriol 173, 2915-2919.

Danielsson, O., Eklund, H. \& Joernvall, H. (1992). The major piscine liver alcohol dehydrogenase has class-mixed properties in relation to mammalian alcohol dehydrogenases of classes I and III. Biochemistry 31, 3751-3759.

Dear, S. \& Staden, R. (1991). A sequence assembly and editing program for efficient management of large projects. Nucleic Acids Res 19, 3907-3911.

Débarbouillé, M., Martín-Verstraete, I., Klier, A. \& Rapoport, G. (1991). The transcriptional regulator LevR of Bacillus subtilis has domains homologous to both $\sigma^{54}$ - and phosphotransferase system-dependent regulators. Proc Natl Acad Sci USA 88, 2212-2216.

Fleischmann, R. D., Adams, M. D., White, O. \& 37 other authors (1995). Whole-genome random sequencing and assembly of Haemophilus influenzae Rd. Science 269, 496-512.

Glaser, P., Kunst, F., Arnaud, M. \& 14 other authors (1993). Bacillus subtilis genome project: cloning and sequencing of the $97 \mathrm{~kb}$ region from $325^{\circ}$ to $333^{\circ}$. Mol Microbiol 10, 371-384.

Harwood, C. R. \& Cutting, S. M. (1990). Molecular Biological Methods for Bacillus. Chichester: Wiley.

Martín, I., Débarbouillé, M., Ferrari, E., Klier, A. \& Rapoport, G. (1987). Characterization of the levanase gene of Bacillus subtilis which shows homology to yeast invertase. Mol Gen Genet 208, 177-184.
Martín-Verstraete, I., Débarbouillé, M., Klier, A. \& Rapoport, G. (1990). Levanase operon of Bacillus subtilis includes a fructosespecific phosphotransferase system regulating the expression of the operon. J Mol Biol 214, 657-671.

Masson, J. Y., Denis, F. \& Brzezinski, R. (1994). Primary sequence of the chitosanase from Streptomyces sp. strain N174 and comparison with other endoglycosidases. Gene 140, 103-107.

Norrander, J., Kempe, T. \& Messing, J. (1983). Construction of improved M13 vectors using oligonucleotide-directed mutagenesis. Gene 26, 101-106.

Parro, V., Hopwood, D. A., Malpartida, F. \& Mellado, R. P. (1991). Transcription of gene involved in the earliest steps of actinorhodin biosynthesis in Streptomyces coelicolor. Nucleic Acids Res 19, 2623-2627.

Pearson, W. R. \& Lipman, D. J. (1988). Improved tools for biological sequence comparison. Proc Natl Acad Sci USA 85, 2444-2448.

Sambrook, J., Fritsch, E. F. \& Maniatis, T. (1989). Molecular Cloning: a Laboratory Manual, 2nd edn. Cold Spring Harbor, NY: Cold Spring Harbor Laboratory Press.

Sanger, F., Nicklen, S. \& Coulson, A. R. (1977). DNA sequencing with chain-terminating inhibitors. Proc Natl Acad Sci USA 74, 5463-5467.

Sharp, P. M., Higgins, D. G., Shields, D. C. \& Devine, K. (1990). Protein-coding genes: DNA sequence data base and codon usage. In Molecular Biological Methods for Bacillus, pp. 557-569. Edited by C. R. Harwood \& S. M. Cutting. Chichester: Wiley.

Stélandre, M., Bosseloir, Y., De Bruyn, J., Maes, P. \& Content, J. (1992). Cloning and sequence analysis of the gene encoding an NADP-dependent alcohol dehydrogenase in Mycobacterium bovis BCG. Gene 121, 79-86.

Wang, Y., Moore, M., Levinson, H. S., Silver, S., Walsh, C. \& Mahler, I. (1989). Nucleotide sequence of a chromosomal mercury resistance determinant from a Bacillus sp. with broad-spectrum mercury resistance. J Bacteriol 171, 83-92.

Wolf, M., Geczi, A., Simon, O. \& Borriss, R. (1995). Genes encoding xylan and $\beta$-glucan hydrolysing enzymes in Bacillus subtilis: characterization, mapping and construction of strains deficient in lichenase, cellulase and xylanase. Microbiology 141, 281-290.

Yoshida, K.-I., Sano, H., Seki, S., Oda, M., Fujimura, M. \& Fujita, Y. (1995). Cloning and sequencing of a $29 \mathrm{~kb}$ region of the Bacillus subtilis genome containing the hut and wapA loci. Microbiology 141, 337-343.

Received 3 July 1996; revised 15 November 1996; accepted 19 November 1996. 